\title{
The Effect of Zinc and Melatonin Supplementation on Lipid Peroxidation of Various Tissues of Rats with by DMBA-Induced Breast Cancer
}

\author{
Elif Gulbahçe-Mutlu ${ }^{1}$ (D), Saltuk Bugra Baltaci 2,* (D) \\ 1 KTO Karatay University, Medical Faculty, Department of Medical Biology, Konya, Turkey \\ 2 Selçuk University, Medical Faculty, Department of Physiology, Konya, Turkey \\ * Correspondence: saltukbugrabaltaci@ selcuk.edu.tr;
}

Scopus Author ID 57196117192

Received: 28.05.2020; Revised: 15.06.2020; Accepted: 16.06.2020; Published: 18.06.2020

\begin{abstract}
The purpose of this study was to investigate the effects of zinc and melatonin administration on lipid peroxidation in various tissues in DMBA-induced breast cancer in female rats. A total of 42 recently weaned Wistar rats were divided into 5 groups in the study: Group 1 (Control), Group 2 (DMBA Control), Group 3 (DMBA+Zinc), Group 4 (DMBA+Melatonin), Group 5 (DMBA+Melatonin, and Zinc). MDA (malondialdehyde) and GSH (glutathione) levels were determined via the spectrophotometric method in the lung, liver, spleen, pancreas, and kidney tissue samples taken from experimental animals. The highest lung, liver, spleen, pancreas, and kidney tissue MDA levels were obtained in the DMBA-induced breast cancer group control group $(\mathrm{G} 2)(\mathrm{p}<0.05)$. MDA levels in DMBA+Zinc (G3), DMBA+Melatonin (G4), and DMBA+Melatonin and Zinc (G5) were significantly lower than group $2(\mathrm{p}<0.05)$. Similarly, lung, liver, spleen, pancreas, and kidney tissue GSH levels of DMBA+Zinc (G3), DMBA+Melatonin (G4), and DMBA+Melatonin and Zinc (G5) were significantly higher than that of Group $2(\mathrm{p}<0.05)$. The findings of the study indicated that increased lung, liver, spleen, pancreas, and kidney damage in DMBA-induced breast cancer is suppressed with the supplementation of zinc, melatonin, and combined zinc and melatonin.
\end{abstract}

Keywords: DMBA; Breast Cancer; MDA, GSH; Zinc; Melatonin.

(C) 2020 by the authors. This article is an open-access article distributed under the terms and conditions of the Creative Commons Attribution (CC BY) license (https://creativecommons.org/licenses/by/4.0/).

\section{Introduction}

Oxidative stress is caused by an imbalance in the body's redox state. In such a case, increased free radicals in the body can cause tissue damage [1]. In such a case, increased free radicals in the body may lead to tissue damage [1]. One of the most important types of free radicals isreactive oxygen species (ROS) produced by various metabolic pathways, including aerobic metabolism in the mitochondrial respiratory chain [1,2]. ROS plays a critical role in the formation and progression of various types of cancer. ROS affects different signal paths, including growth factors and mitogenic pathways. It controls many cellular processes, including cell proliferation, thereby stimulating the uncontrolled growth of cells that promote the development of tumors and initiate the carcinogenesis process [2]. Increased oxidative stress can reduce the antioxidant defense of the body against angiogenesis and metastasis in cancer cells caused by reactive species. These processes are the main factors in the development of cancer [1]. As a result, oxidative stress damages lipids, proteins, and nucleic acids in breast cancer supporting oncogenesis, and tumor progression [2]. Experimental 
evidence suggests that ROS plays a role in the initiation, development, and progression of carcinogenesis, in which tumor suppressor genes are rendered inactive or lose their function in breast cancer [2,3]. It was reported that high levels of oxidant markers and low levels of antioxidants were found in breast cancer [1-3].

Breast cancer is the most common malignant disease among women around the world. It is a heterogeneous disease, and its pathogenesis remains uncertain in most cases [4,5]. Significant progress has been made in the early detection and better treatment of breast cancer [5]. However, organ metastasis is common, especially in people with poor prognosis [4]. Breast cancer cells can spread to remote sites, especially the lung, liver, bone, and brain [5]. The lung, bone, and liver are the most common metastatic target sites for breast cancer [4,5]. Although metastasis to the kidney is rare in clinical practice in breast cancer, there are also reports that it has been observed [6].

Similarly, breast cancer metastases for pancreas is a very rare condition [7]. However, there are publications reporting pancreatic metastasis in breast cancer [8]. Breast cancer accounts for less than 5\% of metastatic pancreatic masses [7]. There are no studies investigating, in combination, oxidative stress and antioxidant activity status in the lung, liver, spleen, pancreas, and kidney tissues, also known as metastatic regions in breast cancer.

The aim of this study was to investigate the effects of zinc and melatonin administration on lipid peroxidation in various tissues in DMBA-induced breast cancer in female rats.

\section{Materials and Methods}

\subsection{Animal material and groups.}

The study included recently weaned (40-day old) female rats of Wistar type. The study protocol was approved by the Selcuk University Experimental Medicine Research and Application Center, Animal Experiment Ethics Committee (2016-31). The 42 female rats included in the study were grouped as follows:

Group 1 (n:6), Control Group: The group was fed on a normal diet and not subjected to any procedure.

Group 2 (n:6), DMBA Control Group: The animals in this group were administered 80 $\mathrm{mg} / \mathrm{kg}$ 7,12-dimethyl[a]anthracene(DMBA) in colza oil (canola) through gavage to induce a tumor and fed on a normal diet.

Group 3 (n:10), DMBA+Zinc Group: The animals in this group were administered 80 $\mathrm{mg} / \mathrm{kg}$ 7,12-dimethyl[a]anthracene (DMBA) in colza oil (canola) through gavage to induce a tumor, and supplemented with $5 \mathrm{mg} / \mathrm{kg} /$ day intraperitoneal (i.p.) zinc along with their normal diet for 4 weeks.

Group 4 (n:10) DMBA+Melatonin Group: The animals in this group were administered $80 \mathrm{mg} / \mathrm{kg}$ 7,12-dimethyl[a]anthracene (DMBA) in colza oil (canola) through gavage to induce a tumor, and supplemented with $5 \mathrm{mg} / \mathrm{kg} /$ day intraperitoneal (i.p.) melatonin along with their normal diet for 4 weeks.

Group 5 (n:10) DMBA+Melatonin and Zinc Group: The animals in this group were administered $80 \mathrm{mg} / \mathrm{kg}$ 7,12-dimethyl[a]anthracene (DMBA) in colza oil (canola) through gavage to induce a tumor, and supplemented with $5 \mathrm{mg} / \mathrm{kg} /$ day intraperitoneal (i.p.) melatonin and zinc combination along with their normal diet for 4 weeks. 


\subsection{Feeding experimental animals.}

The experimental animals were housed in a separate room at the Selcuk University Experimental Medicine Research and Application Center until the end of the study. They were kept in an environment with standard temperature and light $\left(21 \pm 1^{\circ} \mathrm{C}\right.$ and 12-hour dark, 12-hour light). Rats were fed with tap water and rat feed provided by Selcuk University Experimental Medicine Research and Application Center. They were accommodated in special cages, which were cleaned daily. The animals were given 10 grams of feed per 100 grams of body weight.

\subsection{Experimental procedures.}

\subsubsection{Induction of breast cancer.}

To induce breast cancer, 7,12-dimethylbenz[a]anthracene (DMBA) supplied by SigmaAldrich Company (St. Louis, MO, the USA) was used. For this purpose, a single dose of 80 $\mathrm{mg} / \mathrm{kg}$ dimethylbenz[a]anthracene(DMBA) in colza oil (canola) was administered through gavage. One week after the administration, the animals' breast tissues were examined by palpation to check the enlargement of breast tissue. After the enlargement in the breast tissue became evident, 6 rats from among the 36 rats which were administered DMBA were randomly chosen, and their breast tissue samples were collected under general anesthesia. After the presence of the tumor was pathologically detected by light microscopic examination, zinc and melatonin supplementation started (Figure 1). Tumor development was pathologically detected in the 10th week after DMBA administration.

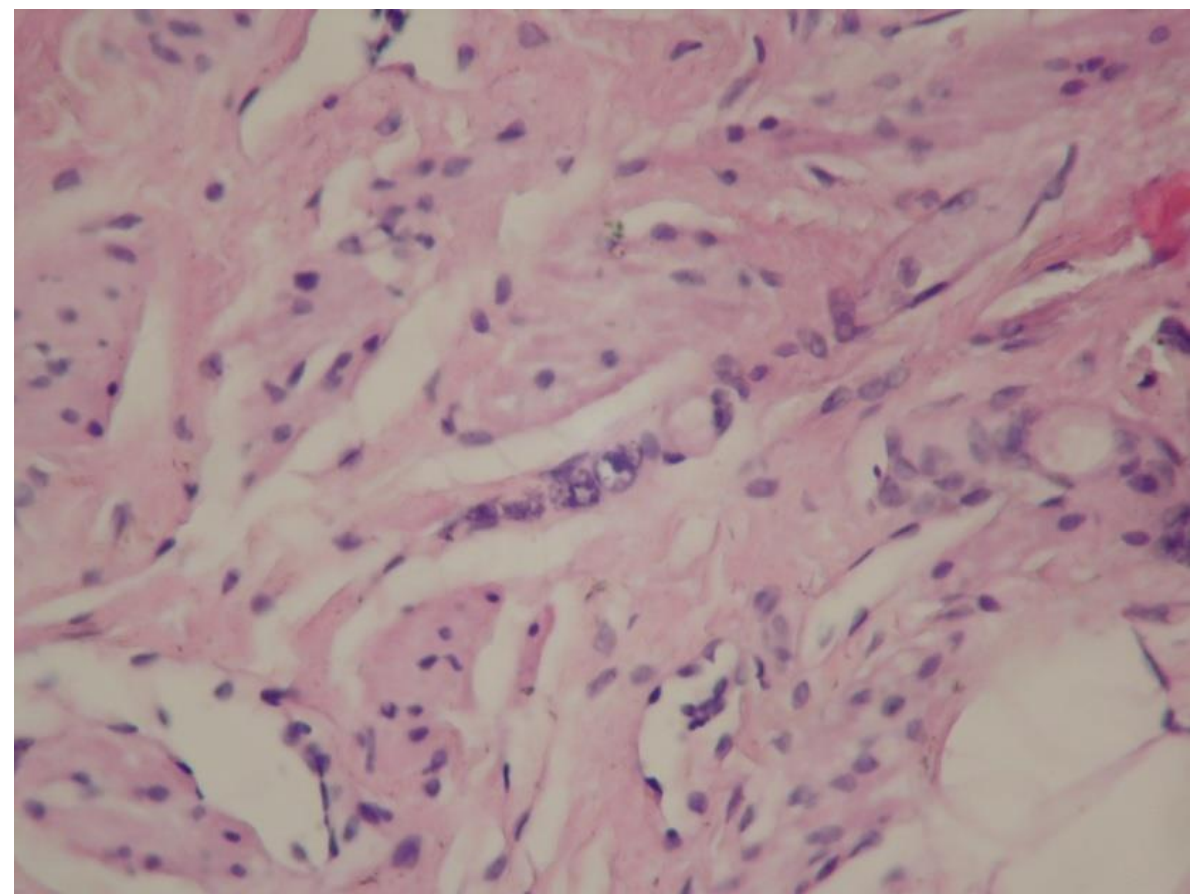

Figure 1. Malignant changes were determined in breast tissue (HE:X40).

\subsubsection{Tissue sample collection.}

After 4-week treatments, lung, liver, spleen, pancreas, and kidney tissue samples were obtained from animals sacrificed under general anesthesia. Tissue samples were kept at $-80^{\circ} \mathrm{C}$ until the time of analysis. 


\subsection{Biochemical analyses.}

2.4.1. Identification of Lung, Liver, Spleen, Pancreas, and Kidney Tissue Malondialdehyde (MDA) Analysis.

MDA analyses in the lung, liver, spleen, pancreas, and kidney tissue were carried out according to TBA (thiobarbituric acid) technique developed by Uchiyama and Miharama [9]. Results of tissue MDA analyses were determined as nmol/gr tissue in the spectrophotometer.

2.4.2. Identification of lung, liver, spleen, pancreas, and kidney tissue glutathione analysis.

GSH in the lung, liver, spleen, pancreas, and kidney tissue was analyzed using the Biuret method as described by Ellman [10], and the results were determined as $\mathrm{mg} / \mathrm{gr}$ tissue.

\subsection{Statistical analysis.}

Statistical evaluation of the results was made with SPSS 22.0 statistical software, and arithmetic means and standard deviations of all parameters were calculated. Kruskal-Wallis $\mathrm{H}$ test was used to determine the differences between the groups, and the Mann-Whitney U test was utilized to find the group causing the difference. $\mathrm{P}<0.05$ values were considered statistically significant.

\section{Results and Discussion}

The highest lung, liver, spleen, pancreas, and kidney tissue MDA levels were obtained in the DMBA-induced breast cancer control $(\mathrm{G} 2)$ group $(\mathrm{p}<0.05)$. MDA levels of DMBA+Zinc (G3) group, DMBA+Melatonin (G4) group, and DMBA + combined melatonin and zinc (G5) group were significantly lower than G2 (Figure 2, p<0.05). In addition, lung, liver, spleen, pancreas and kidney tissue GSH levels of DMBA+Zinc (G3) group, DMBA+Melatonin (G4) group and DMBA+ melatonin and zinc administration group (G5) were significantly higher than DMBA-induced breast cancer control group (G2) (Figure 3, p<0.05).

This study investigated the effects of individual and combined administration of zinc and melatonin on lipid peroxidation in lung, liver, spleen, pancreas and kidney tissues in DMBA-induced female rats.

One of the most commonly used parameters as an indicator of oxidative stress and tissue damage is the determination of MDA levels. For this reason, MDA levels in the lung, liver, spleen, pancreas, and kidney tissues were determined as an indicator of oxidant stress. The highest tissue and plasma MDA levels in our study were obtained in the DMBA (G2) group. Increased oxidative stress parameters have been reported in many experimental studies with DMBA-induced cancer [11-13]. A significant increase in MDA levels in the lung, liver, spleen, pancreas, and kidney tissues of DMBA-induced rats is in parallel with the findings of the studies mentioned above.

The role of oxidative stress is important in many human diseases, including cancer. A wide range of antioxidants has been proposed for the prevention of oxidative stress in humans [14]. Zinc is an essential trace element necessary for the structure and function of a large number of macromolecules, including enzymes that regulate cellular processes and cellular signaling pathways [15]. Zinc modulates the immune response and shows antioxidant and antiinflammatory activity [16]. 
MDA

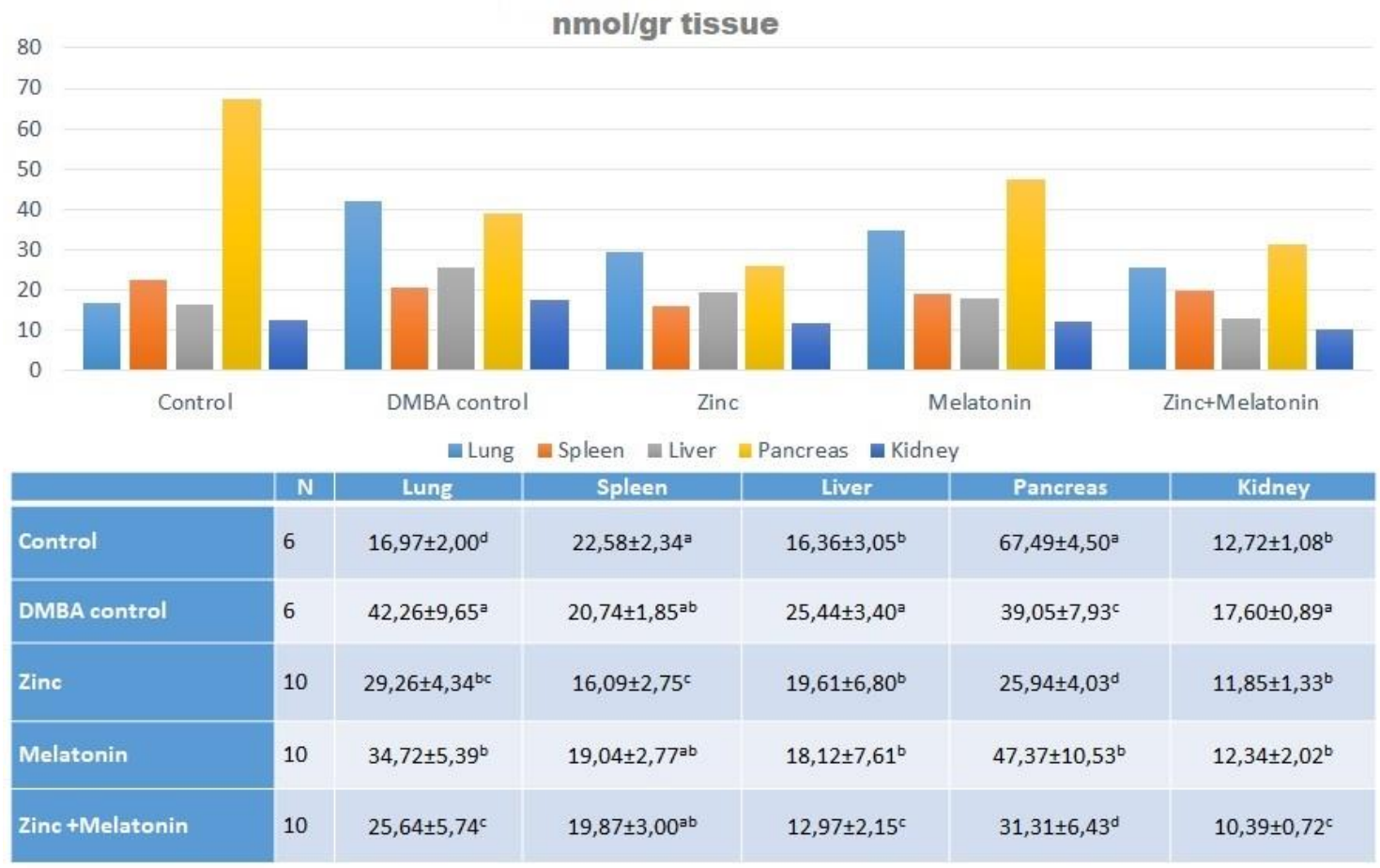

Figure 2. Comparison of MDA Levels in Lung, Spleen, Liver, Pancreas and Kidney tissues of Groups [a, b, c: There was a significant difference between groups in the same column and carrying different letters $(\mathrm{P}<0.05)]$.

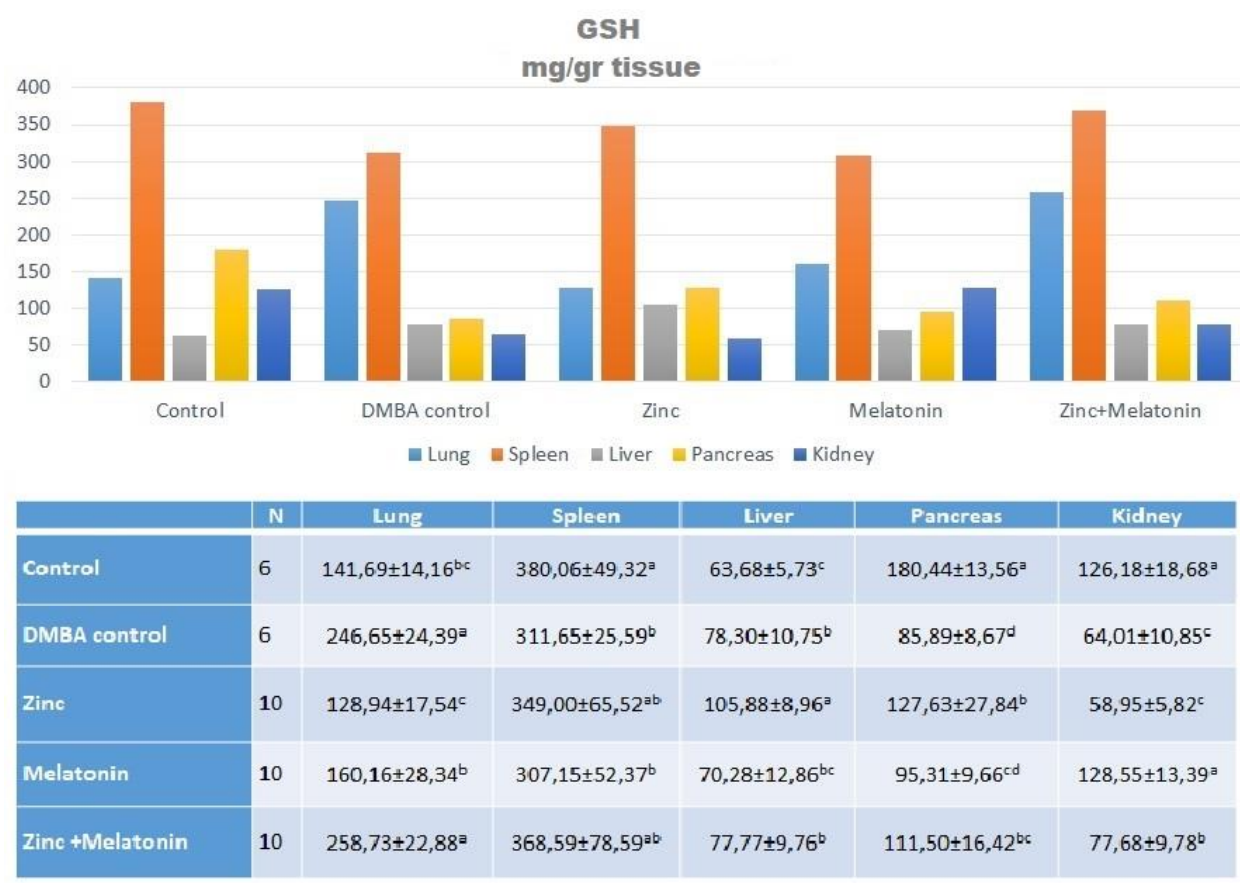

Figure 3. Comparison of GSH Levels in Lung, Spleen, Liver, Pancreas and Kidney tissues of Groups [a, b, c: There was a significant difference between groups in the same column and carrying different letters $(\mathrm{P}<0.05)]$.

Zinc delays oxidative processes in the long term by inducing the expression of metallothioneins. These metal-binding cysteine-rich proteins are responsible for maintaining zinc-related cell homeostasis and function as powerful free radical scavengers [16]. It can replace redox-active metals such as zinc, copper, and iron in certain binding sites and alleviate cellular region-specific oxidative injury $[15,16]$. When the MDA levels of the zincadministered DMBA (G3) group were examined, zinc supplementation caused a significant suppression in tissue MDA levels in comparison to the DMBA-induced (G2) group. Zinc has 
been reported to prevent oxidant stress in the tissues of the lung [17], liver [18], spleen [19], pancreas [20], and kidney [21]. In our study, decreased MDA values in the lung, liver, spleen, pancreas, and kidney tissues obtained in the DMBA-induced group (G3) are consistent with the studies mentioned above.

In many studies, it has been shown that melatonin is associated with oxidative stress and has antioxidant properties as a radical collector directly and indirectly [22,23]. Although melatonin does not need any binding site and receptor for its free radical collecting effect, it can easily pass the blood-brain barrier due to its lipophilic properties [24]. In addition to these properties, it is considered as a very powerful antioxidant because it can eliminate the most harmful radical, hydroxyl radical [24]. In our study, we obtained a finding similar to zinc supplementation in the group where DMBA-induced and melatonin were administered (G4). Compared to the DMBA-induced cancer control group (G2), melatonin supplementation in Group 3 caused a significant suppression in MDA levels in lung, liver, spleen, pancreas, and kidney tissues. Melatonin has been reported to prevent oxidant stress in the tissues of the lung [25], liver [26], spleen [27], pancreas [28], and kidney [29]. In our study, decreased MDA levels in the lung, liver, spleen, pancreas, and kidney tissues in the melatonin administered DMBA-induced group (G3) are in parallel with the findings of the researchers mentioned above.

It was found that MDA levels in the combined zinc and melatonin administered DMBA group (G5), were significantly suppressed in lung, liver, spleen, pancreas, and kidney tissues when compared to DMBA-induced breast cancer group (G2). These results support the view that the combined administration of melatonin and zinc prevents tissue damage [30].

Non-enzymatic antioxidant systems are the second line of defense against free radical damage. GSH is used as a measure for the assessment of antioxidant. It also acts as an antioxidant at the intracellular and extracellular levels [31]. At the same time, it is responsible for protecting the cell against the genotoxic effects of free radicals and protecting against neoplasm by taking part in the immune system [31]. Impaired GSH level is effective in the pathogenesis of many diseases such as cancer and liver diseases [31,32].

In our study, the lowest GSH levels in the lung, liver, spleen, pancreas, and kidney tissues were obtained in the DMBA-induced breast cancer control group (G2). It has been reported that antioxidants, such as both enzymatic and non-enzymatic GSH, decrease in the rat model of DMBA-induced breast cancer [12, 33]. This finding is in line with the studies reporting that antioxidant activity is suppressed in DMBA-induced rats.

We found that the GSH levels of the DMBA groups where zinc (G3), melatonin (G4), and the combination of zinc and melatonin (G5) were administered were significantly higher than DMBA-induced control group (G2). Zinc is considered an anticarcinogenic element. The cancer-preventive effect of zinc is mostly associated with its antioxidant properties [34-36]. Similarly, it is accepted that melatonin prevents cancer development, and this effect is associated with its strong antioxidant activity [37,38]. In addition, the combined administration of melatonin and zinc increases antioxidant activity and prevents tissue damage [30].

\section{Conclusions}

When the results of our study are evaluated as a whole, it shows that increased lung, liver, spleen, pancreas and kidney damage in DMBA-induced breast cancer is suppressed with the support of zinc, melatonin and combined zinc and melatonin. The combined administration 
of zinc and melatonin may contribute to the prevention of lipid peroxidation occurring in tumoral events.

\section{Funding}

This research received no external funding.

\section{Acknowledgments}

This study was supported by the Scientific Research Projects Coordinatorship of Selcuk University (SUBAPK; project no. 16202035).

\section{Conflicts of Interest}

The authors declare no conflict of interest.

\section{References}

1. Hecht, F.; Pessoa, C.F.; Gentile, L.B.; Rosenthal, D.; Carvalho, D.P.; Fortunato, R.S. The role of oxidative stress on breast cancer development and therapy. Tumour Biol 2016, 37, 4281-4291, https://doi.org/10.1007/s13277-016-4873-9.

2. Sateesh, R.; Rao Bitla, A.R.; Budugu, S.R.; Mutheeswariah, Y.; Narendra, H.; Phaneedra, B.V.; Lakshmi, A.Y. Oxidative stress in relation to obesity in breast cancer. Indian J Cancer 2019, 56, 41-44, https://doi.org/10.4103/ijc.ijc_247_18.

3. Nourazarian, A.R.; Kangari, P.; Salmaninejad, A. Roles of oxidative stress in the development and progression of breast cancer. Asian Pac $J$ Cancer Prev 2014, 15, 4745-4751, https://doi.org/10.7314/apjcp.2014.15.12.4745.

4. Alzubi, M.A.; Turner, T.H.; Olex, A.L.; Sohal, S.S,; Tobin, N.P.; Recio, S.G.; Bergh, J.; Hatschek, T.; Parker, J.S.; Sartorius, C.A.; Perou, C.M.; Dozmorov, M.G.; Harrell, J.C. Separation of breast cancer and organ microenvironment transcriptomes in metastases. Breast Cancer Res 2019, 21, https://doi.org/10.1186/s13058-019-1123-2.

5. Jin, L.; Han, B.; Siegel, E.; Cui, Y.; Giuliano, A.; Cui, X. Breast cancer lung metastasis: Molecular biology and therapeutic implications. Cancer Biol Ther 2018, 19, 858-868, https://doi.org/10.1080/15384047.2018.1456599.

6. Xia, D.; Wang, H.; Wang, R.; Liu, C.; Xu, J. High-dose fulvestrant as third-line endocrine therapy for breast cancer metastasis to the left kidney: a case report and literature review. Medicine (Baltimore) 2018, 97, https://doi.org/10.1097/MD.0000000000011115.

7. Kliiger, J.; Gorbaty, M. Metastasis to the pancreas and stomach from a breast cancer primary: a case report. J Community Hosp Intern Med Perspect 2017, 7, 234-237, https://doi.org/10.1080/20009666.2017.1369379.

8. Nakama; Y.; Maruyama, Y.; Hisaka, T.; Yasumoto, M.; Okabe, Y.; Naito, Y.; Yamaguchi, M.; Tanaka, M.; Tanaka, H.; Akagi, Y.; Okuda, K. A vesected case of pancreatic metastasis from breast cancer which recurred six years after breast surgery. Gan To Kagaku Ryoho 2019, 46, 2309-2311

9. Mihara, M.; Uchiyama, M. Determination of malonaldehyde precursor in tissues by thiobarbituric acid test. Anal Biochem 1978, 86, 271-278, https://doi.org/10.1016/0003-2697(78)90342-1.

10. Sedlak, J.; Lindsay, R.H. Estimation of total, protein-bound, and nonprotein sulfhydryl groups in tissue with Ellman's reagent. Anal Biochem 1968, 25, 192-205, https://doi.org/10.1016/0003-2697(68)90092-4.

11. Gan, H.; Zhang, Y.; Zhou, Q.; Zheng, L.; Xie, X.; Veeraraghavan, V.P.; Mohan, S.K. Zingerone induced caspase-dependent apoptosis in MCF-7 cells and prevents 7,12-dimethylbenz(a) anthracene-induced mammary carcinogenesis in experimental rats. $J$ Biochem Mol Toxicol 2019, 33, https://doi.org/10.1002/jbt.22387.

12. Rajendran, J.; Pachaiappan, P.; Subramaniyan, S. Dose-dependent chemopreventive effects of citronellol in DMBA-induced breast cancer among rats. Drug Dev Res 2019, 80, 867-876, https://doi.org/10.1002/ddr.21570. 
13. Zeweil, M.M.; Sadek, K.M.; Taha, N.M,; El-Sayed, Y.; Menshawy, S. Graviola attenuates DMBA-induced breast cancer possibly through augmenting apoptosis and antioxidant pathway and downregulating estrogen receptors. Environ Sci Pollut Res Int 2019, 26, 15209-15217, https://doi.org/10.1007/s11356-019-04920-w.

14. Koekkoek, W.A.; van Zanten, A.R. Antioxidant vitamins and trace elements in critical illness. Nutr Clin Pract 2016, 31, 457-44, https://doi.org/10.1177/0884533616653832.

15. Frassinetti, S.; Bronzetti, G.; Caltavuturo, L.; Cini, M.; Croce, C.D. The role of zinc in life: a review. $J$ Environ Pathol Toxicol Oncol $2006, \quad$ 597-610, https://doi.org/10.1615/JEnvironPatholToxicolOncol.v25.i3.40.

16. Jarosz, M.; Olbert, M.; Wyszogrodzka, G.; Młyniec, K.; Librowski, T. Antioxidant and anti-inflammatory effects of zinc. Zinc-dependent NF- $\mathrm{KB}$ signaling. Inflammopharmacology 2017, 25, 11-24, https://doi.org/10.1007/s10787-017-0309-4.

17. Sacan, O.; Turkyilmaz, I.B.; Bayrak, B.B.; Mutlu, O.; Akev, N.; Yanardag, R. Zinc supplementation ameliorates glycoprotein components and oxidative stress changes in the lung of streptozotocin diabetic rats. Biometals 2016, 29, 239-48, https://doi.org/10.1007/s10534-016-9911-y.

18. Sadhukhan, P.; Kundu, M.; Chatterjee, S.; Ghosh, N.; Manna, P.; Das, J.; Sil, P.C. Targeted delivery of quercetin via $\mathrm{pH}$-responsive zinc oxide nanoparticles for breast cancer therapy. Mater Sci Eng C Mater Biol Appl 2019, 100, 129-40. https://doi.org/10.1016/j.msec.2019.02.096.

19. Li, Y.; Zheng, Y.; Qian, J.; Chen, X.; Shen, Z.; Tao, L.; Li, H.; Qin, H.; Li, M.; Shen, H. Preventive effects of zinc against psychological stress-induced iron dyshomeostasis, erythropoiesis inhibition, and oxidative stress status in rats. Biol Trace Elem Res 2012, 147, 285-291, https://doi.org/10.1007/s12011-011-9319-z.

20. Asani, S.C.; Umrani, R.D.; Paknikar, K.M. Differential dose-dependent effects of zinc oxide nanoparticles on oxidative stress-mediated pancreatic $\beta$-cell death. Nanomedicine (Lond) 2017, 12, 745-759, https://doi.org/10.2217/nnm-2016-0426.

21. Hadj Abdallah, N.; Baulies, A.; Bouhlel, A; Bejaoui, M.; Zaouali, M.A.; Ben Mimouna, S.; Messaoudi, I.; Fernandez-Checa, J.C.; García Ruiz, C.; Ben Abdennebi, H. Zinc mitigates renal ischemia-reperfusion injury in rats by modulating oxidative stress, endoplasmic reticulum stress, and autophagy. J Cell Physiol 2018, 233, 8677-90, https://doi.org/10.1002/jcp.26747.

22. Gurer-Orhan, H.; Ince, E.; Konyar, D.; Saso, L.; Suzen, S. The role of oxidative stress modulators in breast cancer. Curr Med Chem 2018, 25, 4084-4101, https://doi.org/10.2174/0929867324666170711114336.

23. 23.Pérez-González, A.; Galano, A.; Alvarez-Idaboy, J.R.; Tan, D.X.; Reiter, R.J. Radical-trapping and preventive antioxidant effects of 2-hydroxymelatonin and 4-hydroxymelatonin: Contributions to the melatonin protection against oxidative stress. Biochim Biophys Acta Gen Subj 2017, 1861, 2206-2217, https://doi.org/10.1016/j.bbagen.2017.06.016.

24. Reiter, R.J.; Mayo, J.C.; Tan, D.X.; Sainz, R.M.; Alatorre-Jimenez, M.; Qin, L. Melatonin as an antioxidant: under promises but over delivers. J Pineal Res 2016, 61, 253-78, https://doi.org/10.1111/jpi.12360.

25. Tahamtan, R.; Shabestani Monfared, A.; Tahamtani, Y.; Tavassoli, A.; Akmali, M.; Mosleh-Shirazi, M.A.; Naghizadeh, M.M.; Ghasemi, D.; Keshavarz, M.; Haddadi, G.H. Radioprotective effect of melatonin on radiation-induced lung injury and lipid peroxidation in rats. Cell $J$ 2015, 17, 111-120, https://doi.org/10.22074/cellj.2015.517.

26. Jin, C.J.; Engstler, A.J.; Sellmann, C.; Ziegenhardt, D.; Landmann, M.; Kanuri, G.; Lounis, H.; Schröder, M.; Vetter, W.; Bergheim, I. Sodium butyrate protects mice from the development of the early signs of nonalcoholic fatty liver disease: role of melatonin and lipid peroxidation. Br J Nutr 2016, 26, 1682-1693, https://doi.org/10.1017/S0007114516004025.

27. Rastogi, S.; Haldar, C. Comparative effect of melatonin and quercetin in counteracting LPS induced oxidative stress in bone marrow mononuclear cells and spleen of Funambulus pennanti. Food Chem Toxicol 2018, 120, 243-252, https://doi.org/10.1016/j.fct.2018.06.062.

28. Tamtaji, O.R.; Mirhosseini, N.; Reiter, R.J.; Behnamfar, M.; Asemi; Z. Melatonin and pancreatic cancer: Current knowledge and future perspectives. J Cell Physiol 2019, 234, 5372-5378, https://doi.org/10.1002/jcp.27372.

29. Kurhaluk, N.; Szarmach, A.; Zaitseva, O.V.; Sliuta, A.; Kyriienko, S.; Winklewski, P.J. Effects of melatonin on low-dose lipopolysaccharide-induced oxidative stress in mouse liver, muscle, and kidney. Can J Physiol Pharmacol 2018, 96, 1153-1160, https://doi.org/10.1139/cjpp-2018-0011.

30. Kalkan, E.; Ciçek, O.; Unlü, A.; Abuşoglu, S.; Kalkan, S.S.; Avunduk, M.C.; Baysefer, A. The effects of prophylactic zinc and melatonin application on experimental spinal cord ischemia reperfusion injury in rabbits: experimental study. Spinal Cord 2007, 45, 722-730 
31. Bansal, A.; Simon, M.C. Glutathione metabolism in cancer progression and treatment resistance. J Cell Biol 2018, 217, 2291-2298, https://doi.org/10.1083/jcb.201804161.

32. Xiao, Y.; Meierhofer, D. Glutathione Metabolism in Renal Cell Carcinoma Progression and Implications for Therapies. Int J Mol Sci 2019, 20, pii: E3672, https://doi.org/10.3390/ijms20153672.

33. 33.Rocha, K.B.F.; Oliveira, C.N.; Azevedo, Í.M.; Macedo, R.; Medeiros, A.C. Effect of Arrabidaea chica extract against chemically induced breast cancer in animal model. Acta Cir Bras 2019, 34, https://doi.org/10.1590/s0102-865020190100000001.

34. Skrajnowska, D.; Bobrowska-Korczak, B.; Role of zinc in immune system and anti-cancer defense mechanisms. Nutrients 2019, 11, https://doi.org/10.3390/nu11102273.

35. Yazğan, B.; Baltaci, A.K.; Mogulkoc, R.; Avunduk, M.C.; Sahna. E. Effect of zinc sulfate supplementation on metallothionein levels in rat heart tissue with induced ischemia-reperfusion injury. Biointerface Research in Applied Chemistry 2018, 8, 3197-3202.

36. El-Gammal, O.A.; Alsayed Fouda, A.A.; Nabih, D.M. Synthesis, spectral characterization, DFT and in vitro antibacterial activity of $\mathrm{Zn}(\mathrm{II}), \mathrm{Cd}(\mathrm{II})$ and $\mathrm{Hg}(\mathrm{II})$ complexes derived from a new thiosemicarbazide. Letters in Applied NanoBioScience 2019, 8, 715-722, https://doi.org/10.33263/LIANBS84.715722.

37. Talib, W.H. Melatonin and cancer hallmarks. Molecules 2018, 23, https://doi.org/10.3390/molecules23030518.

38. Fernandes, R.T.D.; Franca, E.L.; Triches, D.L.G.F.; Fujimori, M.; Machi, P.G.F. Massmman PF, Tozetti IA, Honorio-Franca AC. Nanodoses of melatonin induces apoptosis on human breast cancer cells co-cultured with colostrum cells Biointerface Research in Applied Chemistry 2019, 9, 4416-4423, https://doi.org/10.33263/BRIAC95.416423. 